\title{
TYROGLYPHUS SIRO, DESTRUCTEUR DES COLLECTIONS \\ DE CULTURES DE CHAMPIGNONS EN FINLANDE
}

\author{
Par Risto PÄTIÄLÄ
}

Les Sarcoptidés de la famille des Tyroglyphidæ sont fréquents dans la nature et $\mathbf{y}$ causent toutes sortes de dégâts, sauf dans la préparation du tabac, où ils sont utiles (M. André) (1). Plusieurs Tyroglyphes provoquent même des maladies, mais c'est surtout sur les aliments et sur d'autres objets conservés dans les maisons qu'ils exercent leur principale action dévastatrice.

Parmi les pertes causées par les Tyroglyphes, celles qui se produisent dans les laboratoires forment une catégorie spéciale : les collections de cultures vivantes de bactéries et de champignons sont souvent attaquées et détruites par ces acariens.

Sur trois tubes voisins de cultures de Ctenomyces granulosus, dans la mycothèque de l'Institut séro-bactériologique de l'Université d'Helsinki, en Finlande, j'ai rencontré, en 1940, le Tyroglyphus siro (Tyrolichus casei Oudemans).

En Finlande, les sarcoptides du genre Tyroglyphus, dont au moins le Tyroglyphus siro est cosmopolite (Neveu-Lemaire), ont été étudiés par Schultze, Vietz et Willman, ce dernier ayant traité du Tyroglyphus siro.

Dès 1873, Mégnin décrit le Tyrolichus rostroserratus, espèce qui détruit les champignons, et, en 1895 , le $T$. mycophagus.

Plus tard, on trouve des renseignements sur les dégâts causés dans les collections par différents acariens, dont les Tyroglyphes, et sur la manière de les combattre dans différents pays (Banks, 1915; Jewson et Tatterfield, 1922 ; Puntoni, 1931 ; Duché, 1933 ; Pease, 1937 ; Langeron, 1942 et 1945 ; Arêa Leāo, 1946).

La contagion dans les cultures se produit généralement par apport extérieur de matériaux d'étude ou autres objets arrivant au laboratoire ; cela dépend de la manière de vivre de ces acariens (André)

(1) Nous tenons à remercier M. Marc André, assistant au Museum national d'histoire naturelle, dont l'aide a beaucoup facilité nos recherches.

ann. de Parasitologie, T. XXII, nos 1-2, 1947, p. 63-64. 
Dans le cas qui nous occupe, l'infection est due à l'apport d'un prélèvement, puisque tous les tubes atteints provenaient d'une source commune.

\section{BibLIOGRAPHIE}

ANDrÉ (M.). - Utilité et applications des études acarologiques, Paris, 1937.

Arêa Leão (A.-E.), de Mello (M.-T.) et Mayor (V.). - Acarinos infestadores de culturas de cogumelos. Mem. Inst. O. Cruz, XLII, 1945.

Banks (N.). - The Acarina or Mites. Report 108. U.S. Depart. of agric., 1915.

Jewson (S.) et TAtTerfield (F.). - The infestation of fungus cultures by mites. Ann. of applied biol., IX, p. 213.

MéGnin (P.). - Les parasites articulés, 1873, 1895.

Neveu-Lemaire (M.). - Traité d'entomologie médicale et vétérinaire. Paris, Vigot, 1938.

Pease (D.). - The insect menace in the bacteriology laboratory. J. of bact., 33, p. 619.

Schultze (P.), Vietz (K.) et Willman (G.). - Mitteilungen ueber F. T. Wasastjarnas Monographia Acarorum. Mem. Soc. Fauna et Flora Fenn., 1937, $\mathrm{n}^{\circ} 13$, p. 121.

Puntoni. - Ann. de paras., XI, 1931, p. 359-362.

DuchÉ (J.). - C.R. Soc. biol., CXII, 1933, p. 124.

Langeron (M.). - Précis de microscopie, 6e édition, Paris, Masson et Cie, 1942, p. 1233-1254, fig. 361. - Précis de mycologie, Paris, Masson et Cie, 1945, p. 506-507.

Institut de Parasitologie de la Faculté de Médecine de Paris (Directeur: Prof. E. Brumpt)

Secition de Mycologie (Chef de service: $D^{r} M$. Langeron) 